
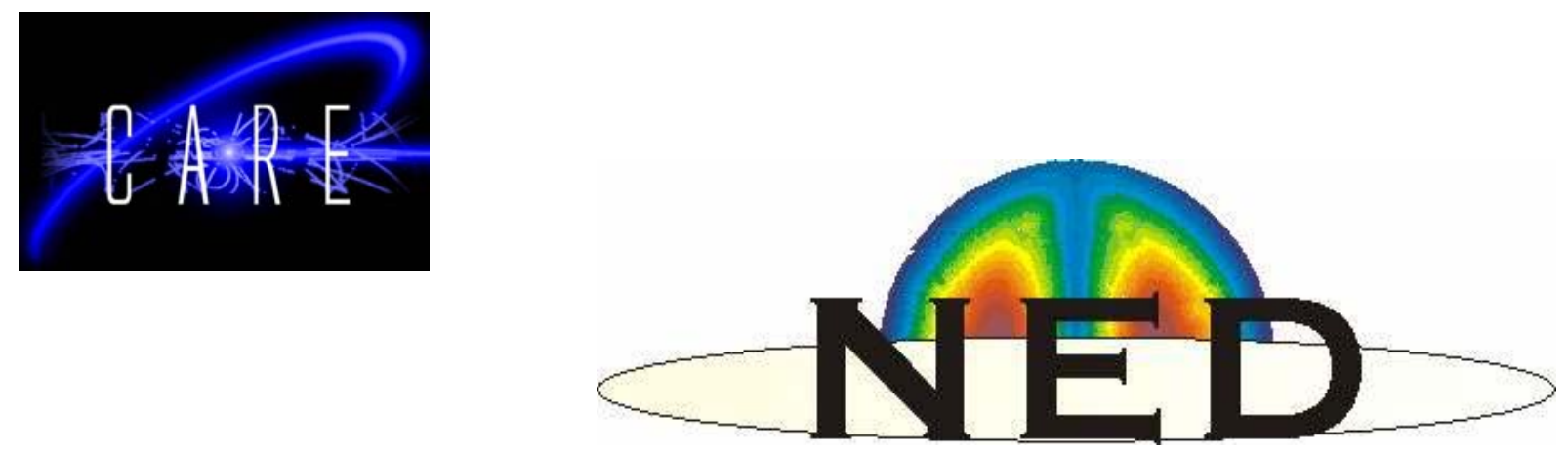

INSULATION DEVELOPMENT FOR THE NEXT EUROPEAN DIPOLE

\author{
S.J. Canfer, D.E. Baynham, R.J.S. Greenhalgh \\ CCLRC, Rutherford Appleton Laboratory, Didcot, OX11 0QX, U.K.
}

\begin{abstract}
Electrical insulation is one of the most challenging issues governing the engineering exploitation of niobium-tin conductors. This is especially true for future accelerator magnets manufactured by the "wind-and-react" route. Applications such as the LHC Interaction Region upgrade or in the longer term an LHC energy upgrade will require magnets to operate at high fields in demanding thermal and radiation environments. The Next European Dipole (NED) programme is aimed at the development of a large aperture (up to 88mm) high field (up to $15 \mathrm{~T}$ conductor peak field) superconducting dipole magnet relying on niobium-tin conductors. Conventional insulation development is being addressed in two key areas, the engineering requirements for large scale magnet manufacture and the improvement of materials properties for magnet operation and performance. The paper will review the status of insulation technology for niobium-tin accelerator magnets and define the special requirements for NED. Particular emphasis will be placed on the development of fibre sizing technology and its influence on magnet manufacture and electrical/mechanical performance of insulation laminates. This work is supported in part by the European Community-Research Infrastructure Activity under the FP6 "Structuring the European Research Area" (CARE, contract number RII3-CT-2003-506395).
\end{abstract}

Contribution to the CEC/ICMC’05, Keystone, USA

Work supported by the European Community-Research Infrastructure Activity under the FP6 « Structuring the European Research Area » programme (CARE, contract number RII3-CT2003-506395). 


\title{
INSULATION DEVELOPMENT FOR THE NEXT EUROPEAN DIPOLE
}

\author{
Canfer S. J., Baynham D. E., Greenhalgh R. J. S. \\ CCLRC, Rutherford Appleton Laboratory, Didcot, OX11 0QX, U.K.
}

\begin{abstract}
Electrical insulation is one of the most challenging issues governing the engineering exploitation of niobium-tin conductors. This is especially true for future accelerator magnets manufactured by the "wind-and-react" route. Applications such as the LHC Interaction Region upgrade or in the longer term an LHC energy upgrade will require magnets to operate at high fields in demanding thermal and radiation environments. The Next European Dipole (NED) programme is aimed at the development of a large aperture (up to $88 \mathrm{~mm}$ ) high field (up to $15 \mathrm{~T}$ conductor peak field) superconducting dipole magnet relying on niobium-tin conductors. Conventional insulation development is being addressed in two key areas, the engineering requirements for large scale magnet manufacture and the improvement of materials properties for magnet operation and performance. The paper will review the status of insulation technology for niobium-tin accelerator magnets and define the special requirements for NED. Particular emphasis will be placed on the development of fibre sizing technology and its influence on magnet manufacture and electrical/mechanical performance of insulation laminates. This work is supported in part by the European Community-Research Infrastructure Activity under the FP6 "Structuring the European Research Area" (CARE, contract number RII3-CT-2003506395).
\end{abstract}

KEYWORDS: niobium-tin superconductor, insulation, fracture, materials testing

PACS: $84.71 \mathrm{ba}, 81.70 \mathrm{q}$

\section{INTRODUCTION}

NED is a 3 year Joint Research Activity (JRA-3) embedded in the Integrated Activity CARE (Coordinated Accelerator Research in Europe). NED focuses on research and development on advanced accelerator magnet technology for existing and future facilities by laying the foundation for an integrated European effort towards bringing $\mathrm{Nb}_{3} \mathrm{Sn}$ technology to maturity and boosting the competitiveness of European laboratories and industry. 
Insulation development is one work package of the NED Joint Research Activity. This paper reviews the current state of the art in insulation technology and presents experimental results on a novel fibre sizing material which shows promise for use in $\mathrm{Nb}_{3} \mathrm{Sn}$ insulation applications.

Accelerator magnets for the Large Hadron Collider are close to the practical limits for NbTi superconductor. Future upgrades to LHC beyond 10 Tesla will require the use of alternative superconducting materials, the most promising material is $\mathrm{Nb}_{3} \mathrm{Sn}$. $\mathrm{Nb}_{3} \mathrm{Sn}$ superconductor is very brittle and strain sensitive [1]. As a result, high-field accelerator

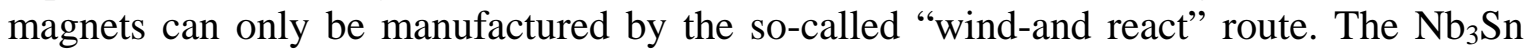
compound is formed from precursors, and after winding the magnet it is subjected to a heat treatment process which forms the $\mathrm{Nb}_{3} \mathrm{Sn}$ compound. This solid state diffusion process typically takes place at temperatures of up to $700^{\circ} \mathrm{C}$ for some days in a vacuum or argon atmosphere, to avoid oxidising the copper stabiliser. This implies that the insulation system must also experience the heat treatment since it is applied to the superconducting cable as part of the winding process.

Electrical insulation is one of the most challenging issues governing the engineering exploitation of $\mathrm{Nb}_{3} \mathrm{Sn}$ conductors.

\section{INSULATION TECHNIQUES FOR NIOBIUM-TIN ACCELERATOR MAGNETS}

In this section we briefly review the status of insulation technology and look at new or innovative developments that are underway. For high field accelerator magnets the Rutherford cable is typically insulated using a glass fibre tape. The insulation needs to be thin to maintain a high superconductor content and overall current density. This in turn dictates the use of thin, 150um, glass fibre tapes.

\section{Conventional insulation}

The conventional approach, established over some 10-20 years has been to use a glass or quartz tape wrap or a braid to insulate the basic cable. In some cases the glass insulation has been supplemented by mica film inserted between the turns, for example the University of Twente 11T dipole [2]. In the earliest applications the tape or braid was applied to the cable with its commercial sizing intact. However, it was found that removal of this sizing at the $\mathrm{Nb}_{3} \mathrm{Sn}$ heat treatment stage was difficult and could lead to poor electrical breakdown strength between turns. Removal of the sizing is now usually done before applying the insulation to the cable. This makes the insulation stage more difficult and the insulation more fragile for winding.

Tape insulation is applied as a double layer wrap to give adequate overlap. Braid insulation can be applied using a specialised machine or for short lengths $\sim 100 \mathrm{~m}$ the braid can be applied as a sleeve to the cable [3].

After insulation the cable is wound using a conventional machine but great care is required in handling of the cable, clamping and forming around the tight bends at the magnet ends, particularly for cos-theta magnet designs. After winding the coil is clamped in a mould and undergoes the heat treatment process of, typically, one week at $660^{\circ} \mathrm{C}$. Heat treatment is carried out in a vacuum or inert (argon) atmosphere. During heat treatment there is a risk of damage due to expansion movements. This risk will be increased for the long coils required for future accelerators.

After heat treatment the glass is extremely fragile and great care is required if the coil is to be transferred from a heat treatment mould to an impregnation mould. The final stage in coil manufacture is vacuum impregnation with epoxy. This is a relatively complex process with some risk of failure. It also represents a significant cost for large 
scale magnet production. Impregnation with epoxy means that helium is excluded from the winding and can play no part in coil stability or heat removal (except at the coil surfaces).

While many variants/improvements on the conventional insulation route have been developed, the basic process remains similar to the one developed for some of the earliest $\mathrm{Nb}_{3} \mathrm{Sn}$ filamentary magnets[4].

\section{SIZING}

The commercial sizing applied after glass filament drawing is a mixture of organic materials. The sizing has many functions: to enable high-speed weaving by providing a protective layer, to protect the glass surface from damage and fracture and also to protect weaving machines from the abrasive nature of the glass. Some manufacturers use a starch size for weaving purposes which is removed before a functional sizing is applied, depending on the application. A functional sizing includes materials to chemically couple the glass to the matrix in order to increase fibre-to-matrix bond strength, and wetting agents. The sizing is a thin coating that is approximately $1-2 \%$ of the weight of the fibre[5].

A typical commercial glass sizing is not intended for high-temperature use, such as experienced during the $\mathrm{Nb}_{3} \mathrm{Sn}$ reaction cycle. Commercial sizings degrade during heat treatment but do not oxidise in the vacuum or argon environment. A carbon residue is left on the glass. This compromises electrical breakdown strength and cannot be tolerated because high voltages can be generated during a magnet quench. Therefore the most common approach is to remove the sizing from the glass fibre before cable wrapping.

\section{Desizing}

A typical approach is to remove the sizing by heating the glass tape to 350-450C in air before winding the cable[3,6]. The effect of removing the sizing is to leave the glass fibre vulnerable to damage during winding. The lack of a functional sizing and a wetting agent is likely to reduce the fibre to matrix bond strength.

\section{Resizing}

Arkan [3] reports the use of palmitic acid to reinstate the lubrication function of a size. Palmitic acid is removed during heat treatment and is reported to leave little carbon residue.

Sizing is very desirable for ease of cable wrapping and magnet winding. This will be especially so if larger scale magnet production is required for a future particle accelerator. The ideal sizing material would provide protection to the fibres during tape winding, and provide compatibility between the inorganic fibre and organic matrix. This is considered to be essential for high shear strength and fracture toughness in the final insulation. We have therefore taken the approach of looking for a sizing that survives heat treatment.

A literature search identified polyimide materials as a promising sizing material for this application. Polyimide materials are amongst the most thermally stable polymers because their chemical structure is highly aromatic. A family of polyimide materials have been developed at NASA Langley Research Centre for high temperature composite applications. They have been commercialised, for example by UBE [7]. Hydrosize Technologies Inc. market a polyimide material for use as a sizing for polyimide resin transfer moulding applications [8]. It is rated to $500^{\circ} \mathrm{C}$ in air. Since the $\mathrm{Nb}_{3} \mathrm{Sn}$ reaction 
takes place in an oxygen-free environment to avoid oxidising the conductor's copper stabiliser, it was thought that the maximum service temperature could be increased and that this sizing might therefore be useful for $\mathrm{Nb}_{3} \mathrm{Sn}$ insulation.

\section{Novel/Innovative}

A more radical approach is to replace the organic sizing with an inorganic or ceramic precursor. This approach is being developed at CEA Saclay[9] and separately by CTD Inc[10]. In this approach the glass tape is impregnated with a ceramic precursor which fully penetrates the tape fibres. The tape is used to wrap the cable in the conventional way for coil winding.

The standard heat treatment to form the $\mathrm{Nb}_{3} \mathrm{Sn}$ also achieves the heat treatment of the ceramic to give a robust insulation and a structurally complete coil. The coil will still have some porosity and the aim is to remove the impregnation stage. For this to be possible the insulation bonded with ceramic must have sufficient mechanical and electrical integrity for magnet assembly and operation. If some porosity can be maintained then helium will penetrate the winding to aid stability. The innovative programme is not reported in this paper.

\section{EXPERIMENTAL STUDIES}

A specification for the NED insulation material has been formulated. It includes mechanical, electrical, thermal and tentative radiation resistance parameters [11].

Since the parameter space for candidate insulation materials is so large, three screening tests have been used to economically test key material properties, namely interlaminar fracture toughness, shear strength, and electrical breakdown strength. The screening tests have been carried out at a temperature of $77 \mathrm{~K}$ rather than $4 \mathrm{~K}$ for expediency. More comprehensive testing of a few candidate materials to the specification will be carried out towards the end of the NED Insulation Development Programme.

Work of fracture is considered to be an important material property as fracture can lead to magnet instability and quenches. A standard test method was chosen, ASTM D5528, which can be applied to composites made using heat treated glass fibre and used to give a quantitative measure of work of fracture. It can also be performed at low temperature.

Standardised composite laminates were produced using a process representative of magnet insulation, with the exception that S-glass fibre fabric measuring $150 \mathrm{~mm} \mathrm{x}$ $150 \mathrm{~mm}$ was used, and not tape; and that the laminates measured approximately $3 \mathrm{~mm}$ in thickness to enable mechanical testing. Heat treatment was carried out in a stainless steel tool in a vacuum furnace.

\section{Interlaminar work of fracture testing}

Interlaminar fracture test ASTM D5528 has already been shown to be a useful test at low temperature by Shindo et al [13]. Shindo found that work of fracture (G) increases at $77 \mathrm{~K}$ then falls back to approximately room temperature values at $4 \mathrm{~K}$. Therefore room temperature is a suitable environment for screening test purposes. The test yields many results per sample and sample preparation is relatively straightforward.

Two sets of tests were performed. Firstly, in order to apply this technique to our current programme it was necessary to perform validation test studies. Secondly the effect of heat treatment and a polyimide sizing was investigated. 


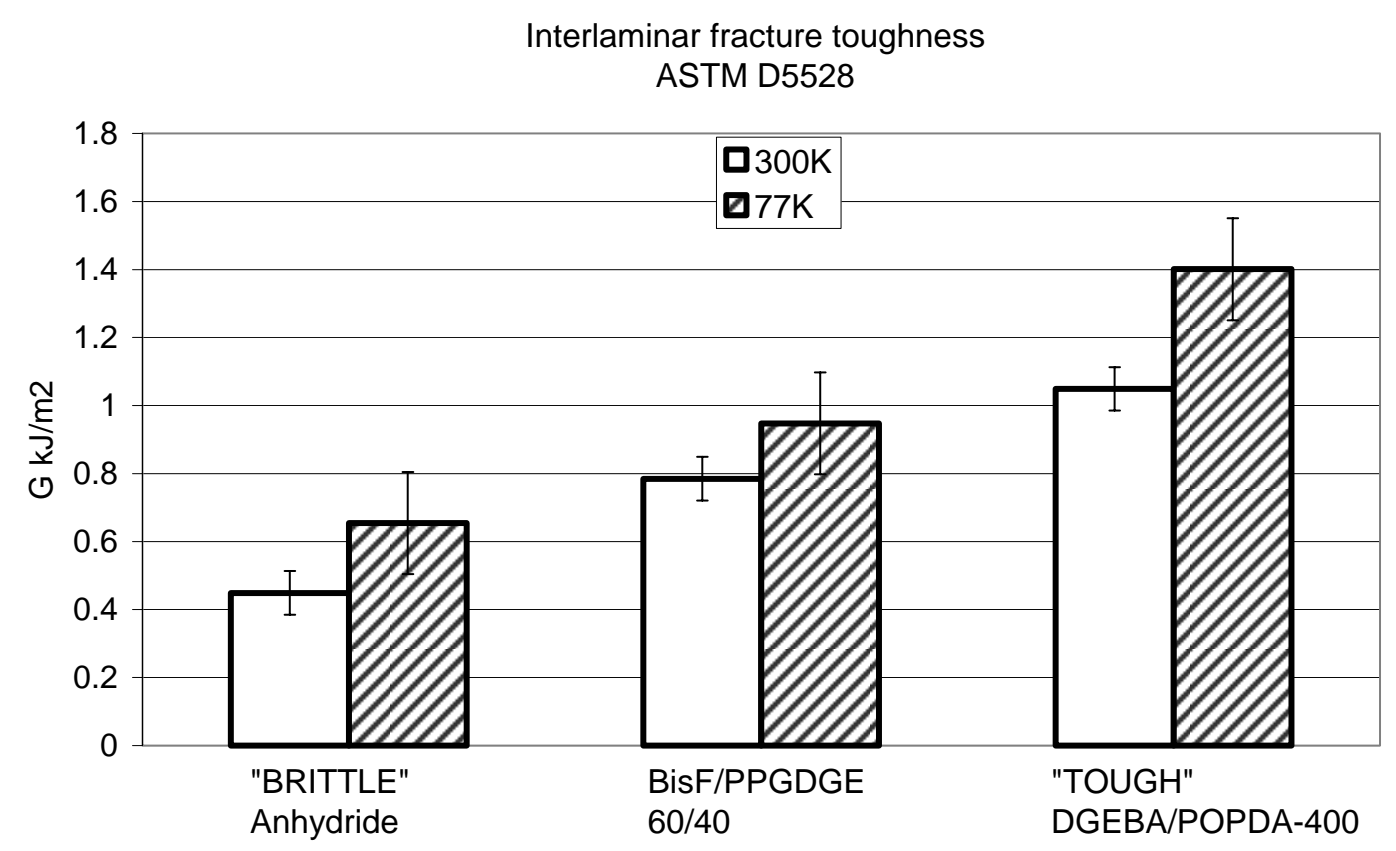

FIGURE 1. Work of fracture $(\mathrm{G})$ validation test results. E glass fabric reinforcement with three epoxy systems, tested at $300 \mathrm{~K}$ and $77 \mathrm{~K}$.

\section{Work of fracture validation tests}

Fracture testing was carried out on known tough and brittle resin systems to gain experience of the test technique and to replicate Shindo's results. Tests were performed at ambient temperature and at $77 \mathrm{~K}$ in liquid nitrogen. All validation tests were made using Eglass fibre. Results of these validation tests are presented in Figure 1.

The brittle epoxy is DGEBA with an acid anhydride hardener (HY918, Ciba), and is considered the standard epoxy for superconducting magnets as it has many production advantages. The tough epoxy is DGEBA with an aliphatic amine hardener (Jeffamine D400). This has a shorter working time compared to the anhydride. The results in the centre of the chart are for an epoxy formulated for the ATLAS End Cap Toroids which combines toughness with sufficient working time for impregnation of large magnets [12]. It uses DGEBF epoxy, PPGDGE flexibiliser and an aromatic amine hardener, (HY5200, Ciba).

The results enable a quantitative comparison of the toughness of these resin systems to be made for the first time.

\section{Effect of polyimide sizing and heat treatment on work of fracture}

The effect of desizing the glass was investigated. Three types of fabric were used. Sglass from SP Systems was used as a reference material. JPS Glass supplied S-glass and quartz fabric, both treated with a polyimide sizing.

Laminates were produced by vacuum impregnation of the glass fibre with an epoxy resin at 40C. An epoxy matrix was chosen which is both relatively radiation stable, and has low viscosity so it is an epoxy that could be suitable for this application[12]. The epoxy is DGEBF (DER354P, Dow) and DETDA (HY5200, Vantico). Curing was performed in a press at a pressure of $5 \mathrm{MPa}$ and temperature of $80^{\circ} \mathrm{C}$ for 16 hours followed by $130^{\circ} \mathrm{C}$ for 24 hours. The fibre content of laminates was 50 to $55 \mathrm{vol} \%$. 
Table 1 summarises the results obtained.

Laminate 1 was used as a reference material; the work of fracture is as expected from a brittle matrix. The short beam shear strength of 94MPa is close to the NED specification of 100MPa [11]. Laminate 2 contained desized S-glass and showed a surprisingly high work of fracture result. Laminate 3, desized then heat treated to simulate the $\mathrm{Nb}_{3} \mathrm{Sn}$ process, failed through the glass layers and not in an interlaminar fashion. This is an invalid test result so a quantitative result is meaningless. This result indicates that the glass was adversely affected by the heat treatment.

Laminate 4 provides reference data for polyimide sized S-glass before heat treatment. It is higher than the commercially sized S-glass (0.70 compared to $0.49 \mathrm{~kJ} / \mathrm{m} 2)$, which is encouraging considering that the polyimide sizing was not intended for compatability with epoxies, but for a polyimide matrix. Results for laminate 5, after heat treatment, show the same work of fracture and an increase in shear strength. This may be due to the vacuum heat treatment completing the curing process of the water-based polyimide sizing.

Quartz fibre showed the highest work of fracture, $0.88 \mathrm{~kJ} / \mathrm{m} 2$.

The fracture surfaces were examined using SEM. The polyimide-treated glass shows little evidence of fibre breakage compared to the reference $S$ glass (laminate 1), see Figures 2 and 3.

\section{Short Beam Shear testing}

Short-beam shear testing to ASTM D2344 was performed to examine the fibre to matrix bond strength. Results are presented in Table 1 .

All laminates that had been heat treated at $660 \mathrm{C}$ failed in a tensile or partly tensile manner. In contrast, all non-heat treated laminates failed in shear. This indicates that the strength of the glass has been affected by the heat treatment.

Laminate 5, JPS glass with polyimide sizing after heat treatment, shows the highest shear strength. The mode of failure is partly shear.

Quartz fibre exhibited a low shear strength compared to the S-glass, (64 compared to 98MPa).

TABLE 1 Interlaminar fracture and short-beam-shear test results of laminates with S-glass fibre and DGEBF/DETDA epoxy matrix

\begin{tabular}{|c|c|c|c|c|c|}
\hline $\begin{array}{l}\text { Laminate } \\
\text { Reference }\end{array}$ & Fabric & Sizing & Heat treatment & $\begin{array}{c}\text { Work of } \\
\text { fracture, G } \\
\mathrm{kJ} / \mathrm{m} 2 \\
\text { at } 300 \mathrm{~K} \\
\end{array}$ & $\begin{array}{c}\text { Short beam } \\
\text { shear strength } \\
\text { MPa at } 77 \mathrm{~K} \\
\text { (failure mode) }\end{array}$ \\
\hline 1 & S-glass & $\begin{array}{c}\text { Commercial (as } \\
\text { received) }\end{array}$ & None & 0.49 & $94(\mathrm{~S})$ \\
\hline 2 & S-glass & Desized & $\begin{array}{l}\text { 350C 16hours } \\
\text { in air }\end{array}$ & 0.85 & $97(S)$ \\
\hline 3 & S-glass & Desized & $\begin{array}{c}\text { 350C 16hours } \\
+660 \mathrm{C} \\
\text { 60hours in } \\
\text { vacuum } \\
\end{array}$ & $\begin{array}{l}\text { Invalid result, } \\
\text { glass fracture }\end{array}$ & $69(\mathrm{~T})$ \\
\hline 4 & JPS S-glass & Polyimide & None & 0.70 & $89(\mathrm{~S})$ \\
\hline 5 & JPS S-glass & Polyimide & $\begin{array}{c}\text { 660C } 60 \text { hours } \\
\text { in vacuum }\end{array}$ & 0.67 & $98(\mathrm{~S}+\mathrm{T})$ \\
\hline 6 & JPS Quartz & Polyimide & $\begin{array}{l}660 \mathrm{C} 60 \text { hours } \\
\text { in vacuum }\end{array}$ & 0.88 & $64(\mathrm{~T})$ \\
\hline
\end{tabular}




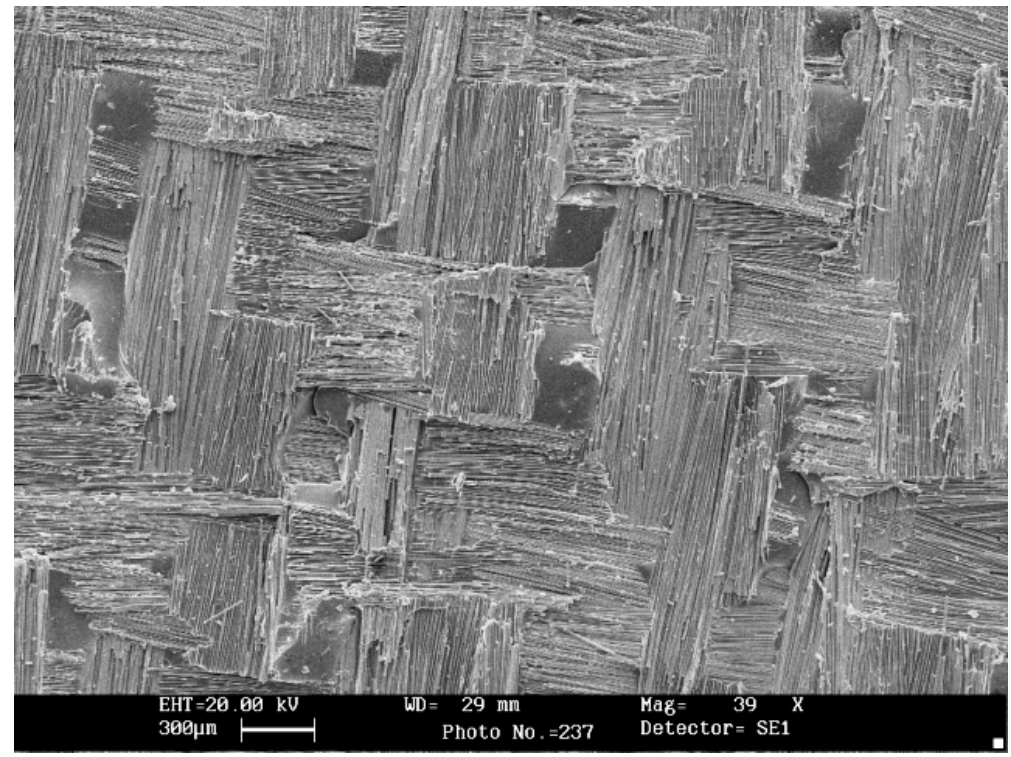

FIGURE 2. Fracture surface of laminate ref.4, desized and heat treated

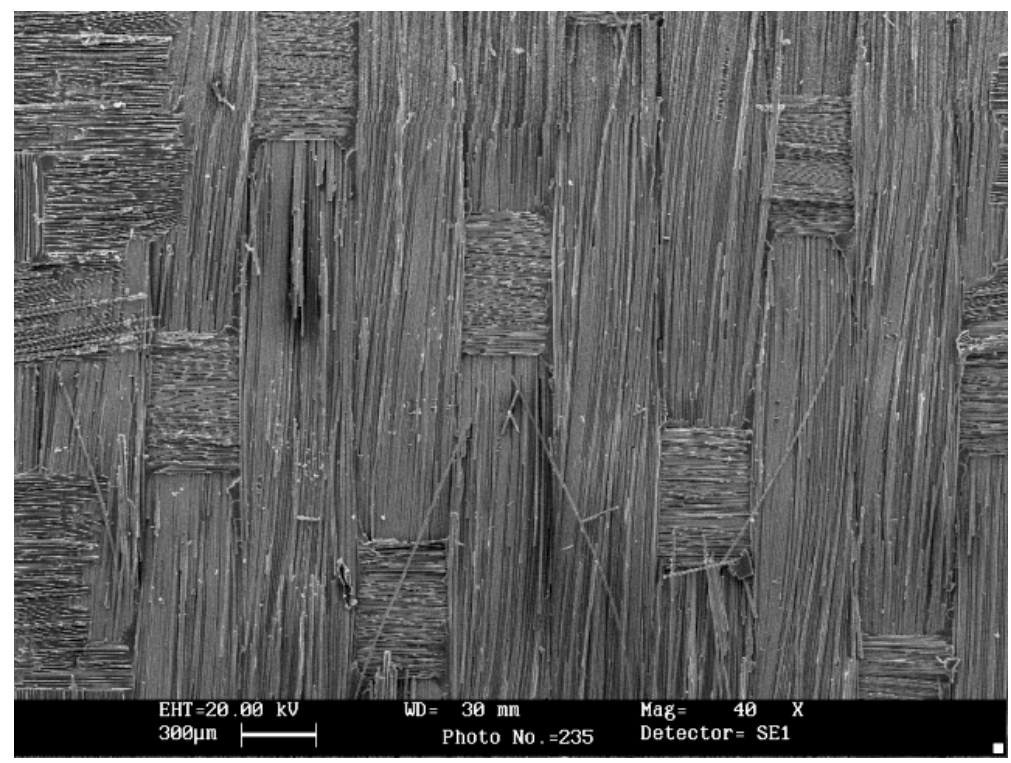

FIGURE 3. Fracture surface of laminate ref. 6, polyimide sizing and heat treated

\section{Electrical breakdown testing}

Electrical breakdown test to BS7831 is included because of the tendency for conventional sizing materials to degrade to carbon, and reduce electrical breakdown strength. A key specification requirement is breakdown strength of $5 \mathrm{kV} / \mathrm{mm}$. A G10 GRP material without carbon should withstand $30 \mathrm{kV} / \mathrm{mm}$ so this is a modest specification.

Tests were carried out on laminates $0.4 \mathrm{~mm}$ in thickness, manufactured at the same time as the thicker laminates for mechanical tests.

Electrical breakdown test results are presented in Table 2. 
TABLE 2: Results of electrical breakdown test to BS7831

\begin{tabular}{cccc}
\hline Fabric & Heat treatment & Colour of laminate & $\begin{array}{c}\text { Breakdown voltage } \\
\mathrm{kV} / \mathrm{mm}\end{array}$ \\
\hline S glass & Desized + 660C vacuum & White & $>30$ \\
\hline S glass & 660 C vacuum & Dark grey & 2.5 \\
\hline S glass + polyimide sizing & 660 C vacuum & Light grey & $>30$ \\
\hline
\end{tabular}

The polyimide sized glass has high electrical breakdown strength after heat treatment. The colour change is from white to light grey, confirming that there is little carbon residue arising from thermal degradation.

\section{CONCLUSIONS}

A polyimide glass sizing material promises to solve many of the practical problems facing insulation manufacture for niobium-tin superconducting magnet applications.

Three test methods have been used to economically screen materials for insulation applications, interlaminar fracture, short beam shear and electrical breakdown voltage. The polyimide sizing on S-glass delivers improvements in all three parameters.

\section{ACKNOWLEDGEMENT}

This work is supported in part by the European Community-Research Infrastructure Activity under the FP6 "Structuring the European Research Area" (CARE, contract number RII3-CT-2003-506395).

\section{REFERENCES}

1. Ekin J. W., "Strain effects in superconducting compounds”, in Advances in Cryogenic Engineering (Materials), 30, edited by A. F. Calrk et al., Plenum, New York, 1984, pp. 823-836.

2. den. Ouden A. et al., IEEE Trans. on Magnetics 30, No. 4, pp. 2320 - 2323 (July 1994)

3. Arkan et al, Studies on S-2 fiber glass insulation for Nb3Sn cable, Fermilab TD98-063 (1998)

4. Apsey R. Q. et al., "Filamentary Niobium-Tin Hexapole magnet”, in Sixth International Conference on Magnet Technology, ALFA Bratislava, 1978, pp546-550.

5. Campbell F. C., Manufacturing Processes for Advanced Composites, Elsevier Oxford, 2004, p44

6. Devred A. et al., "Insulation systems for Nb3Sn accelerator magnet coils fabricated by the "wind and react” technique”, Advances in Cryogenic Engineering 46A (Materials), edited by U. B. Balachandran et al., New York 2000, pp143-150.

7. http://www.upilex.jp/catalog/pdf/peti330.pdf

8. http://www.hydrosize.com/products/high_performance/hp-1621/

9. http://at-hhh-amt.web.cern.ch/at\%2Dhhh\%2Damt/Presentations/Rondeaux.pdf

10. Bittner-Rohrhofer K. et al, "Characterization of reactor irradiated organic and inorganic hybrid insulation systems for fusion magnets”, in Advances in Cryogenic Engineering 48A, edited by U. B. Balachandran et al., New York 2002, pp261-268

11. Devred A. et al., Status of the Next European Dipole (NED) Activity of the Collaborated Accelerator Research in Europe (CARE) project, CERN/AT report 2005-2

12. Evans D. and Canfer S. J., "A new resin system for the impregnation and bonding of large magnet coils", Proc. 17th Int. Cryo. Eng. Conf., Institute of Physics, London, 1998 pp467-470.

13. Shindo et al., J. Eng. Mat. Tech. 123, pp191-197 (2001). 